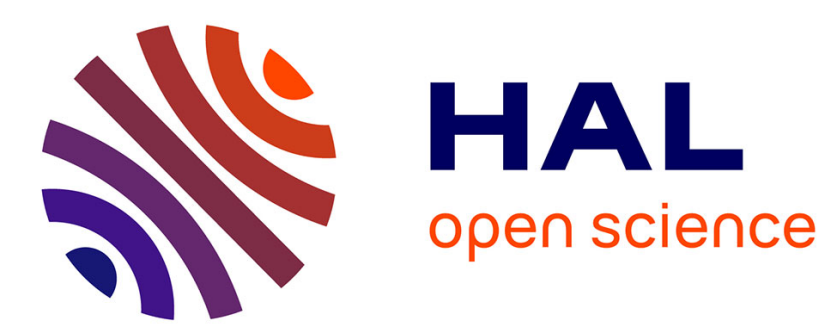

\title{
DNA detection method based on the two-dimensional aggregation and selective desorption of nanoparticle probes
}

\author{
A. Charrier, N. Candoni, F. Thibaudau
}

\section{- To cite this version:}

A. Charrier, N. Candoni, F. Thibaudau. DNA detection method based on the two-dimensional aggregation and selective desorption of nanoparticle probes. Journal of Physical Chemistry B, 2006, 110 (26), pp.12896-12900. 10.1021/jp061616z . hal-00105749

\author{
HAL Id: hal-00105749 \\ https://hal.science/hal-00105749
}

Submitted on 19 Mar 2019

HAL is a multi-disciplinary open access archive for the deposit and dissemination of scientific research documents, whether they are published or not. The documents may come from teaching and research institutions in France or abroad, or from public or private research centers.
L'archive ouverte pluridisciplinaire HAL, est destinée au dépôt et à la diffusion de documents scientifiques de niveau recherche, publiés ou non, émanant des établissements d'enseignement et de recherche français ou étrangers, des laboratoires publics ou privés. 


\title{
A DNA detection method based on
}

\section{the 2D aggregation and selective desorption}

\author{
of nanoparticle probes
}

Anne Charrier*, Nadine Candoni, Franck Thibaudau

CRMCN, CNRS, Université de la Méditerranée, Marseille, France

*charrier@crmcn.univ-mrs.fr 


\begin{abstract}
A label-free two-dimensional colorimetric DNA sensor is reported. This sensor is based on the 2D aggregation of oligonucleotide modified gold nanoparticle probes induced by the molecular hybridization of single stranded oligonucleotide probes and their complementary single stranded DNA targets. To detect the aggregation, we have developed a new detection method based on the selective desorption of non-aggregated nanoparticles. We will show here that this detection method is highly specific and allows the quantification of the DNA targets.
\end{abstract}

Keywords: DNA sensor, gold nanoparticles, aggregation, desorption, molecular hybridization 


\section{Introduction}

A major challenge in DNA detection and identification is the development of methods that do not rely on the labeling (fluorescent or radioactive) of target DNA. Most direct DNA detections are based on the molecular hybridization between single stranded DNA probes and their complementary single stranded DNA targets ${ }^{1-3}$. Among these detection methods many studies have been carried out over the past few years using DNA modified gold nanoparticle probes. Mirkin et al. first studied such a technique in the late 90 ' $\mathrm{s}^{4-6}$. They showed the possibility of linking the nanoparticles through hybridization with a target DNA, leading to the formation of nanoparticle aggregates of micrometer dimensions. This phenomenon induces a color change from red for free particles in solution to blue for aggregated ones, providing the base for a direct colorimetric detection of the target DNA in solution. However, because this method is performed in solution, it is not suitable for multiplexing detections such as DNA chips ${ }^{7}$. One way to overcome this problem is to use DNA arrays and nanoparticle probes ${ }^{8-13}$. In such experiments two different probes functionalize the substrate and gold colloids. When they are joined with target DNA complementary to both probes, they can hybridize, linking the nanoparticles to the substrate. The nanoparticles are used here as a label indicating the presence of complementary target DNA in the solution. These techniques are applicable to multiplexed detection but they involve numerous processes, especially when high sensitivity is desired where a thorough rinsing to remove the non hybridized gold nanoparticles is required. Moreover, in contrast with what has been done in $3 \mathrm{D}$ these experiments do not use the aggregation properties between the nanoparticles. As shown by Taton et al. ${ }^{9}$, this leads to a decrease in specificity compared with the 3D method.

In this paper, we present a new detection method based on the $2 \mathrm{D}$ aggregation of DNA modified gold nanoparticle probes on a supported fluid layer. The great originality of this sensor arises from the transduction method used to determine the presence of hybridized 
DNA. The aggregation detection is colorimetric, but in contrast with the previously described method by Mirkin and al., the color change is based on the selective desorption of the nanoparticles from the substrate, depending on their 2D aggregation. We show that our system conserves the specificity properties of the 3D aggregated nanoparticles. Moreover, as the nanoparticles are on a supported surface, the system offers the possibility of multiplexed detection.

A schematic of the two-dimensional sensor we have developed is given in figure 1. It is composed of a lipid layer supported on a solid substrate on which DNA modified gold nanoparticles are adsorbed by electrostatic interactions. Our interest in using a lipid layer to support the nanoparticles is due to its two-dimensional fluidity, which we assume allows the nanoparticles to move along the surface ${ }^{14}$. In a typical sensor, there are two sets of gold nanoparticles adsorbed at an equal ratio on the lipid layer. Each set had been previously modified by oligonucleotides of sequences A and B respectively (see table 1). This sensor is able to recognize a target sequence containing the complementary sequence (DNA C) to both the probe sequences $\mathrm{A}$ and $\mathrm{B}$. The hybridization between the target and the mobile nanoparticle probes is believed to create links between the nanoparticles resulting in the formation of 2D nanoparticle aggregates.

\section{MATERIALS AND METHODS}

\section{DNA and reagents}

All DNA sequences were purchased from Eurogentec (Belgium). The phospholipids (1,2Dimyristoyl-sn-Glycero-3-Ethylphosphocholine (Chloride Salt), (EDMPC)) were purchased from Avanti Polar Lipids (Alabaster, AL) in a powder form. The lipids were diluted in chloroform at $10 \mathrm{mg} / \mathrm{ml}$ and kept in the freezer at $-20^{\circ} \mathrm{C}$ (stocked solution). Hydrogen 
tetrachloroaurate (III), 99.9\% was purchased from Alfa Aesar Johnson Matthey (Germany). All other reagents were obtained from Sigma-Aldrich (St Louis, MO).

Table 1 DNA probes and targets used in this study

\begin{tabular}{|c|c|}
\hline Oligonucleotides Probes & $\begin{array}{l}\text { A: 5'SH- }\left(\mathrm{CH}_{2}\right)_{6}-(\mathrm{T})_{20}-\mathrm{GTCAGACTTTCG}-3 ' \\
\text { B: 5'-TCCATTGCGGAA- }(\mathrm{T})_{20}-\left(\mathrm{CH}_{2}\right)_{3}-\mathrm{SH} 3 \text { ' }\end{array}$ \\
\hline Complementary DNA target to A and B & C: 5'-TTCCGCAATGGACGAAAGTCTGAC-3' \\
\hline
\end{tabular}

Control experiment:

Non complementary DNA to A and B

E: 5'-TACGAGTTGAGAATGCTGAATGCG-3'

Oligonucleotide Probes

F : 5' SH- $\left(\mathrm{CH}_{2}\right)_{6}-(\mathrm{T})_{10}$-TTAATGCACTT-3'

G: 5'- AATTAATAGCTT(T) $)_{10}-\left(\mathrm{CH}_{2}\right)_{3}$-SH 3'

Complementary DNA target to F and G

H : 5'-AGCTATTAATTAAGTGCATTAA-3'

Preparation of 3'- and 5' -(thiol)Oligonucleotides-modified gold nanoparticles (NPs)

The gold colloids were prepared by trisodium citrate reduction of gold tetrachloaurate, following literature procedures with minor modifications ${ }^{6}$. Briefly, $50 \mathrm{ml}$ of $1 \mathrm{mM} \mathrm{HAuCl}_{4}$ is heated while agitated with a magnetic stirrer. When boiling point is reached, $5 \mathrm{ml}$ of $38.8 \mathrm{mM}$ trisodium citrate are added to the solution. At this point, the solution color changes from light yellow to dark red. Boiling is maintained for 15 minutes before cooling the solution to room temperature. Using this procedure, $\sim 13 \mathrm{~nm}$ of gold nanoparticles are obtained. 
Gold nanoparticles are modified by adding thiolated oligonucleotides to a final concentration of $3.6 \mu \mathrm{M}$. The nanoparticle solution is then maintained at $50^{\circ} \mathrm{C}$ for 40 hours, before being brought to $0.1 \mathrm{M} \mathrm{NaCl}$. After 40 more hours at $50^{\circ} \mathrm{C}$, the excess oligonucleotides are removed by centrifugating the solution, removing the supernatant and diluting the solution again in 0.1 $\mathrm{M} \mathrm{NaCl}$. This rinsing procedure is repeated three times. The resulting DNA modified gold nanoparticles (NPs) carry a negative surface charge provided by the anionic thiolated oligonucleotides.

\section{Preparation of the lipid layer}

The lipid layer is formed by the fusion of phospholipidic vesicles on the substrate. In all the experiments, EDMPC lipids were used. EDMPC are fluid at ambient temperature and carry a positive charge on their headgroup ${ }^{15,16}$. Ten microlitres of $10 \mathrm{mg} / \mathrm{ml}$ EDMPC are taken from the stocked solution and left at ambient temperature to evaporate off the chloroform. $100 \mu$ of $0.1 \mathrm{M} \mathrm{NaCl}$ are then added to the lipids and the solution is sonicated for 30 minutes to form vesicles. The substrate, which can be organic or inorganic, needs to carry a negative or neutral surface charge to facilitate the lipids adsorption. In our case the supports are $2 \mathrm{~mm}$ diameter glass beads, chosen for manipulation convenience. Typically, 50 uncolored glass beads are washed in methanol and hydrogen peroxide and introduced into a $2 \mathrm{ml}$ microtube filled with $0.1 \mathrm{M} \mathrm{NaCl}$. The latter is added with the solution of EDMPC (at $1 \mathrm{mg} / \mathrm{ml}$ ) in $\mathrm{NaCl}$ at $0.1 \mathrm{M}$ and left at ambient temperature for 12 hours. After the lipid layer has formed, the glass beads are then thoroughly rinsed with $0.1 \mathrm{M} \mathrm{NaCl}$ to remove the excess lipids in the solution and kept in $0.1 \mathrm{M} \mathrm{NaCl}$ solution. 


\section{Adsorption of the oligonucleotide modified gold nanoparticles}

Two types of gold nanoparticles carrying different DNA sequences are mixed together at a 1:1 ratio. Subsequent to the lipid adsorption and rinsing, this NP solution is added to the beads. The NPs adsorb on the lipid layer by electrostatic forces. Those NPs which do not adsorb are removed after 30 minutes by rinsing with a $0.1 \mathrm{M} \mathrm{NaCl}$ solution. The remaining beads are colored red (described hereafter as "bead sensor"). The density of adsorbed NPs on the layer has been estimated to be $\sim 10^{11} \mathrm{~cm}^{-2}$ using atomic force microscopy.

\section{Hybridization}

In all the described experiments, the bead sensors are incubated for $30 \mathrm{~min}$ in $20 \mu \mathrm{l}$ of a 300 mM Na phosphate buffer with a DNA solution of 1-2 $\mu 1$. At such a buffer concentration we have verified that the NPs in solution (3D) do aggregate through the hybridization of the DNA target. Longer incubation time does not change our results.

\section{Sensitivity experiments}

In a sensitivity experiment, the bead sensors are hybridized as described above with varying quantities of complementary DNA and 1 pmol of non-complementary DNA. After incubation, $0.5 \mathrm{mg} / \mathrm{ml}$ dextran sulfate solution is added to make the NPs desorb. After 4 minutes, all the desorption product is collected and poured into the spectrophotometer cuvette. Finally, this cuvette is filled to a total volume of $500 \mu \mathrm{l}$ with $0.3 \mathrm{M} \mathrm{Na}$ phosphate buffer and the absorbance at $527 \mathrm{~nm}$ is measured using a Cary 1E spectrophotometer from Varian.

\section{RESULTS AND DISCUSSION}

Firstly, the bead sensor was incubated for a few days in a hybridization solution with a large amount of complementary target $(1 \mathrm{nmol})$. Unexpectedly, this did not lead to a color change 
from red to blue as observed for the aggregation in solution by Storhoff et al. ${ }^{17}$. We will show in what follows however that NPs form 2D aggregates on the beads' surface. Storhoff attributed the color change to the formation of large 3D aggregates of thousands of nanoparticles ${ }^{18}$. For small aggregates this color change is not detectable by the naked eye. The absence of color change in our case suggests the $2 \mathrm{D}$ aggregates are small. Therefore, the color change used in the 3D system by Storhoff et al. as a colorimetric detection signal can not be used with our $2 \mathrm{D}$ system. To reveal the NPs aggregation we have developed a new method based on the desorption properties of the NPs. This method consists in adding chemical species to the solution which are able to compete with the NPs adsorbed on the lipid layer, thereby promoting their desorption. These species were chosen among anions. We have, to this point, found that $\mathrm{Cl}^{-}, \mathrm{Br}^{-}$, and negative polymer dextran sulfate display such properties. In the following, we present only those results concerning the desorption using dextran sulfate. In such a test, dextran sulfate is added to the solution after hybridization to a final concentration of $0.5 \mathrm{mg} / \mathrm{ml}$. When the hybridization is carried out with only noncomplementary DNA (E, or sonicated salmon sperm DNA), the addition of dextran sulfate provokes the complete NPs' desorption from the bead sensor within a few seconds. This desorption induces a discoloration of the sample and a red coloration of the solution. (fig. 2ae). In contrast, when the hybridization is carried out with complementary DNA (C) no desorption occurs after introduction of the dextran sulfate in the solution. The sample then remains red and the solution uncolored (fig. 2f-j). The same result is obtained after hybridization with a mix of complementary DNA (C, 1 pmol) and a much larger amount of non-complementary DNA ((E, $1 \mathrm{nmol}$ or $1 \mu \mathrm{g}$ of sonicated salmon sperm DNA)). Therefore the presence of non-complementary DNA does not prevent the hybridization. This desorption test provides a simple colorimetric detection without any rinsing process. These experiments clearly show that hybridization stabilizes the NPs on the sensor. But the question remains 
whether or not the NPs aggregation occurs. To answer this question we performed the same experiments with a sensor prepared with only one type of NP (type A). For this sensor, the complementary target can hybridize on the NPs but cannot form links between them. In this case, the NPs desorbed after the dextran sulfate test, showing that this kind of hybridization is not a sufficient condition to stabilize the NPs. Therefore, the stabilization and the nondesorption of the NPs originate from the cross-linking hybridization of the NPs, i.e. their aggregation.

This property is very interesting because in $3 \mathrm{D}$, Mirkin et al. ${ }^{4}$ have shown that the collective behavior of the aggregated NPs increases the specificity of the detection. In the following section we will estimate this specificity for our 2D system.

\section{Specificity of the detection method}

One way to estimate the specificity of the method is to study the melting properties of duplex DNAs. When a mismatched pair is present in the duplex DNA sequence, the melting process is initiated by the mismatch at a temperature usually lower than the melting temperature of a perfectly matching duplex DNA. This property is being exploited in a variety of tests for the detection of mutations or polymorphisms. However, for free-standing DNAs in solution or for DNA chips, this melting is not an abrupt transition but occurs over a large range of temperatures (typically $15^{\circ} \mathrm{C}^{5}$ ). The presence of a mismatch in a duplex DNA sequence induces a typical temperature shift of $2-5^{\circ} \mathrm{C}$, which is quite small with respect to the large melting temperature width of the transition. This leads to a low contrast of the hybridization ratio between a mismatched and a perfectly matching target. However, Elghanian et al. ${ }^{5}$ have shown that this "melting temperature width" is drastically reduced for the gold nanoparticle/DNA complex in solution (down to $4^{\circ} \mathrm{C}$ for $13 \mathrm{~nm}$ gold nanoparticles). This behavior is of great interest because it provides a functional template for high specificity 
DNA detection. The narrower the melting transition, the higher the specificity of the detection system will be.

The "melting" temperature width of our system is evaluated by monitoring the NPs desorption by absorption spectrophotometry at $527 \mathrm{~nm}$. In this experiment, the bottom of a polystyrene spectrophotometer cuvette is used as a substrate. Complementary target (100 pmol $\mathrm{C}$ or D) in $300 \mathrm{mM}$ phosphate buffer is added in the cuvette to link the A and B nanoparticles. After hybridization at room temperature, the cuvette is filled with a $0.5 \%$ dextran sulfate, $300 \mathrm{mM}$ phosphate buffer solution and placed in a thermostated spectrometer. The absorption of the solution at $527 \mathrm{~nm}$ is measured while the temperature is increased continuously $\left(0.2^{\circ} \mathrm{C} / \mathrm{min}\right)$. Below the "melting temperature", the NPs do not desorb and no absorption signal is measured. As the temperature is increased, the 2D aggregates "melt", and due to the presence of dextran sulfate in the solution the non-aggregated NPs desorb and are released into the solution. The solution absorption then increases until all the nanoparticles are desorbed. The result of such an experiment is shown in figure 3. The width of the transition $\left(\mathrm{W} \approx 4.5^{\circ} \mathrm{C}\right.$ ) is narrower than that obtained by Taton and Jin for nanoparticles hybridized with a probe immobilized on a substrate $\left(\mathrm{W} \approx 7^{\circ} \mathrm{C}\right)^{6,9}$ and is similar to widths obtained for 3D nanoparticles aggregation systems ${ }^{6}$. The presence of a mismatch in the linking sequence induces a $4.5^{\circ} \mathrm{C}$ temperature shift towards the lower temperatures. At $52^{\circ} \mathrm{C}$, the NPs of the cuvette hybridized with the mismatched sequence are completely desorbed while those hybridized with the matching one have not yet begun to desorb. These results show the highly specific character of our detection system. 


\section{Quantification of the detection}

In figure $4 \mathrm{a}$, three different bead sensors hybridized with 0,100 and $200 \mathrm{fmol}$ of complementary DNA (C) respectively, are shown after the desorption test. For 200 fmol, no desorption can be observed, the sensor remains colored red. For $100 \mathrm{fmol}$, one can observe a partial desorption of the NPs from the substrate. The solution color changes from transparent to light red and the glass bead from dark red to lighter red. This desorption is complete when no DNA is present in the solution. These results are very interesting since they suggest that quantitative measurements are possible. To address this property, we carried out experiments to quantify the NPs in the desorption product with respect to the amount of target. The amount of NPs in the desorption product is measured by absorption spectrophotometry at 527 $\mathrm{nm}$. We used bead sensors (with a diameter of $2 \mathrm{~mm}$ ) incubated in $20 \mu 1$ of hybridization solution containing $1 \mathrm{nmol}$ of non-complementary DNA (E) and the quantity of complementary DNA (C) varied from 1000 fmol to 0 fmol. For each quantity of target, the absorption measurements are presented in figure $4 \mathrm{~b}$ for three different sets of sensors. These sets display different densities of NPs, i.e. they are more or less colored. Two regimes can be determined. Above a certain quantity of complementary target which corresponds to a saturation quantity ( $\sim 200$ fmol for the full triangles curve), no desorption occurs. Below this saturation quantity, the absorbance decreases proportionally to the quantity of DNA target.. Absorbance measurement of the desorption product then allows the quantification of the target. For each set of sensors, the initial amount of NPs on the beads can be estimated by considering the absorbance at 0 fmol of targets, i.e. when no hybridization occurs and when all the nanoparticles desorb from the substrate after addition of the dextran sulfate (a calibration of the absorbance was first performed for varying amounts of NPs in the solution). For the three sets of sensors, we found $1.9 \times 10^{10}, 9.6 \times 10^{9}$ and $6.5 \times 10^{9}$ particles for the full triangle set, the open circle set and the full square set respectively (see figure $4 \mathrm{~b}$ ). The 
corresponding sensitivity curves show that the target saturation quantity decreases with the initial number of nanoparticles on the sensor. The DNA saturation quantity versus this quantity of nanoparticles on the sensor is reported for the three sets of sensors in the figure $4 \mathrm{~b}$ inset. From this curve, it is clear that the saturation quantity is proportional to the quantity of nanoparticles on the sensor. One can deduce from the slope of the line, that the saturation quantity per nanoparticle is 6 DNA targets. Moreover, the target saturation quantity is roughly the same when varying the hybridization solution volume from $20 \mu l$ to $500 \mu l$ i.e varying the target concentration. This shows that the stabilization of the nanoparticles on the surface is limited by the quantity of target DNA in the hybridization solution and not by its concentration. Hence, decreasing the sensor size, i.e decreasing the number of nanoparticle probes, leads to the reduction of the target saturation quantity in the same proportion (data not shown here). According to our results, a typical saturation quantity is $\sim 10 \mathrm{fmol}$ per $\mathrm{mm}^{2}$ of sensor surface. A reduction of the support size to $10^{-3} \mathrm{~mm}^{2}$ as for a DNA chip would lead to a saturation quantity of about 10 amol of target.

\section{Multiplexing experiments}

As NPs are adsorbed on a supported surface, our system offers some possibilities to build multiplex DNA detection systems. We will present here a simple example. Different bead sensors using differently colored substrates can be fabricated to detect different targets, each color being assigned to a given target. When the gold nanoparticles (red) are adsorbed on the colored glass beads, the beads color changes. This property is used to detect the desorption or non desorption of the NPs after the addition of dextran sulfate. In a typical experiment, differently colored sensors are incubated together in the same hybridization solution. After 30 minutes of hybridization, $0.5 \mathrm{mg} / \mathrm{ml}$ dextran sulfate is added to the solution. The NP probes that have not been hybridized desorb from their glass bead, which recovers its initial color 
(before adsorption of the NPs). Finally, the DNA hybridization is easily probed by looking at the glass beads' colors with a color camera or even with the naked eye if the sensor is big enough. We carried out such an experiment and the result is shown in figure 5 for two different DNA targets and four different colored glass beads. On the red and the dark brown beads, gold nanoparticles modified with oligonucleotides probes of types A and B have been adsorbed. These beads detect the target DNA C. The orange and light brown beads carry F and $\mathrm{G}$ oligonucleotides probes detecting target DNA H. Four beads of each color have been apportioned in four different wells. In addition to a $300 \mathrm{mM} \mathrm{Na}$ phosphate buffer solution, wells 1, 2, 3 and 4 contain 500 pmol of each DNAs C and H, only 500 pmol of DNA H, only 500 pmol of DNA C and no DNAs respectively. Picture a. shows the four wells at the beginning of the experiment. Picture $b$. has been taken after addition of dextran sulfate to the four wells and finally picture c. was taken after rinsing the wells with a $300 \mathrm{mM} \mathrm{Na}$ phosphate buffer solution. In picture b., one can clearly observe a desorption of the gold nanoparticles in the wells 2, 3 and 4. As expected no desorption occurs in well 1 where all the DNA probes should be hybridized and a desorption from the four beads occurs in well 4 where no complementary DNA had been added to any of the beads. In well 2, only the darkbrown and red beads desorb and in well 3, only the orange and light-brown beads, are in perfect agreement with the target DNAs introduced into each well. The change of the color of the bead from before desorption of the nanoparticles to after their desorption can be seen more easily in picture c. after rinsing. The red bead becomes nearly transparent, the orange becomes yellow, the light brown, light green and the dark brown becomes dark green. The example described here is for four different bead colors, but it can be multiplexed with many others. 


\section{Conclusions}

We have developed a DNA detection sensor based on the two-dimensional aggregation of gold nanoparticles. In contrast with 3D aggregation, our 2D system does not present any colorimetric change from red to blue. This is due to the very small size of the aggregates. To detect the aggregation, we have developed a new colorimetric method based on the selective desorption of the nanoparticles from the surface which allows quantitative measurements.

Our system conserves the specificity of the aggregation properties of the $3 \mathrm{D}$ system. In addition, as a 2D supported system, it enables the design of multiplexed detection. Finally, compared to other supported methods using nanoparticles, its implementation is very simple: after incubation of the sensor in the hybridization solution, the subsequent detection does not require any additional steps, such as incubation with nanoparticles or rinsing.

(1) Pouthas, F.; Gentil, C.; Cote D.; Bockelmann, U. App. Phys. Lett. 2004, 84, 1594-1596

(2) Souteyrand, E.; Cloarec, J. P.; Martin, J. R.; Wilson, C.; Lawrence, I.; Mikkelsen, S. and Lawrence, M. F. J. Phys. Chem. B. 1997, 101, 2980-2985

(3) Thiel, A. J.; Frutos, A. G.; Jordan, C. E.; Corn, M. R.; Smith, L. M. Anal. Chem. 1997, $69,4948-4956$

(4) Li, Z.; Jin, R.; Mirkin, C. A.; Letsinger, R. L. Nucleic Acids Res. 2002, 30, 1558-1562

(5) Elghanian, R.; Storhoff, J. J.; Mucic, R. C.; Letsinger, R. L.; Mirkin, C. A. Science $1997,277,1078-1081$

(6) Jin, R.; Wu, G.; Li, Z.; Mirkin, C. A.; Schatz, G. C. J. Am. Chem. Soc. 2003, 125, $1643-$ 1654

(7) Epstein, J. R.; Biran, I.; Walt, D. R. Anal. Chim. Acta 2002, 469, 3-36

(8) Cao, YW. C.; Jin, R.; Mirkin, C.A. Science 2002, 297, 1536-1539 
(9) Taton, T. A.; Mucic, R. C.; Mirkin, C. A.; Letsinger, R. L. J. Am. Chem. Soc. 2000, 122, $6305-6306$

(10) Taton, T.A. ; Mirkin, C.A. ; Letsinger, R.L. Science 2000, 289, 1757-1760

(11) Park, S.-J.; Taton, T.A.; Mirkin, C.A. Science 2002, 295, 1503-1505

(12) Su, M.; Li, S.; Dravid V.P. Appl. Phys. Lett. 2003, 82, 3562-3564

(13) Mao, X.; Yang, L.; Su, X. -L.; Li, Y. Biosens. Bioelectron. 2006, 21, 1178-1185

(14) MacDonald, R. C.; Ashley, G. W.; Shida, M. M.; Rakhmanova, V. A.; Tarahovsky, Y.S.; Pantazatos, D. P.; Kennedy, M. T.; Pozharski E. V.; Baker, K. A.; Jones, R. D.; Rosenzweig, H. S.; Choi, K. L.; Qiu, R. Z.; McIntosh, T. J. Biophys. J. 1999, 77, 26122629

(15) Koynova, R.; MacDonald, R. C. Biochim. Biophys. Acta 2005, 1714, 63-70

(16) Charrier, A.; Thibaudau, F. Biophys. J. 2005, 89, 1094-1101

(17) Storhoff, J. J.; Elghanian, R.; Mucic, R. C.; Mirkin, C. A.; Letsinger, R. L. J. Am. Chem. Soc. $1998,120,1959-1964$

(18) Storhoff, J. J.; Lazarides, A. A.; Mucic, R. C.; Mirkin, C. A.; and Letsinger R. L.; Schatz, G. C. J. Am. Chem Soc. 2000, 122, 4640-4650 


\section{Figure Captions}

Figure 1. a) Schematic of the detection device. The system consists of three layers constituted by an organic or inorganic substrate (glass, polymer, $\mathrm{SiO}_{2}, \mathrm{Si}_{2} \mathrm{~N}_{3}, \mathrm{Mica}$ ), a lipid layer and oligonucleotides modified gold nanoparticles (NPs). b) Principle of NPs assembling through DNA hybridization. Two sets of NPs are prepared with different single stranded probe oligonucleotides. Addition of complementary target DNA to the solution leads to the NPs aggregation through the hybridization of the targets DNA with the probes oligonucleotides. c) A top view schematic of the system before and after hybridization.

Figure 2: Pictures of the desorption of a non hybridized sample (a-e), and non-desorption of a hybridized sample (f-j), after addition of dextran sulfate at successive time intervals between $\mathrm{t}=0 \mathrm{~s}$ and $\mathrm{t}=20 \mathrm{~s}$. The solution is continuously agitated.

Figure 3. Melting curves of the DNA duplex linking the NPs of type A and B to single strands in $300 \mathrm{mM}$ phosphate buffer solution. In this experiment, 1 pmol of complementary target DNA (C) and 1 nmol of non-complementary DNA (E) have been used to link the NPs. The dissociation is indirectly monitored by absorption spectrophotometry at $527 \mathrm{~nm}$ by the measurement of the nanoparticle desorption from the surface after deshybridization. These curves have been obtained for a) a perfect complementary target DNA (C) and b) a complementary DNA target presenting one mismatch (D). The corresponding derivative curves are shown in the inset.

Figure 4. a) Picture showing three different sensors hybridized with 0,100 and 200 fmol of complementary DNA after addition of dextran sulfate. The desorption depends on the amount 
of complementary DNA in the hybridization solution showing that quantification is possible. b) Experimental results showing the sensitivity of the system. In this experiment, three sets of sensors with different densities of NPs and prepared as described in the text were immerged in a $300 \mathrm{mM}$ phosphate buffer solution containing an amount of complementary target DNA which varied from 1000 fmol to 0 fmol and $1 \mathrm{nmol}$ of non-complementary DNA. After 30 minutes, the solution was brought to $0.5 \mathrm{mg} / \mathrm{ml}$ dextran sulfate to promote the desorption. The resulting desorption product was subsequently measured by absorption spectrophotometry. For each set of measurements, the saturation quantity versus the quantity of NPs on the glass beads is shown in the inset.

Figure 5: Four sets of differently colored glass beads have been prepared. Four beads of each set have been apportioned in four different wells. NPs targeting DNA C and DNA $\mathrm{H}$ have been respectively adsorbed on the orange/light brown and on the dark brown/red glass beads. Picture a. shows the sensors at the beginning of the experiment. 500 pmol of DNAs C and $\mathrm{H}$ were added to the well 1 . Respectively 500 pmol of DNAs $\mathrm{H}$ and $\mathrm{C}$ were added to the wells 2 and 3. The well 4 does not contain any complementary DNA. Picture b. shows the same sensors after addition of dextran sulfate and picture c. after rinsing the wells. No desorption occurs in well 1 showing that both DNAs C and $\mathrm{H}$ were present. Only the NPs from the dark brown and red glass beads have desorbed in well 2 and only the orange and light brown ones have desorbed in well 3. The NPs from all the beads have desorbed in well 4 confirming the absence of both $\mathrm{C}$ and $\mathrm{H}$ DNAs in the well. 
a)

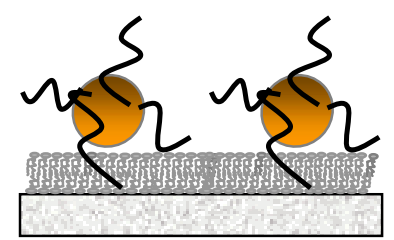

b)

$\varepsilon_{2}^{2}+\mathrm{VN} \rightarrow$ commin

c) $\{\sim q, q\}$

$\sim \sum_{s} \sim$

s

$\{\operatorname{lov} \varepsilon$

Figure 1 

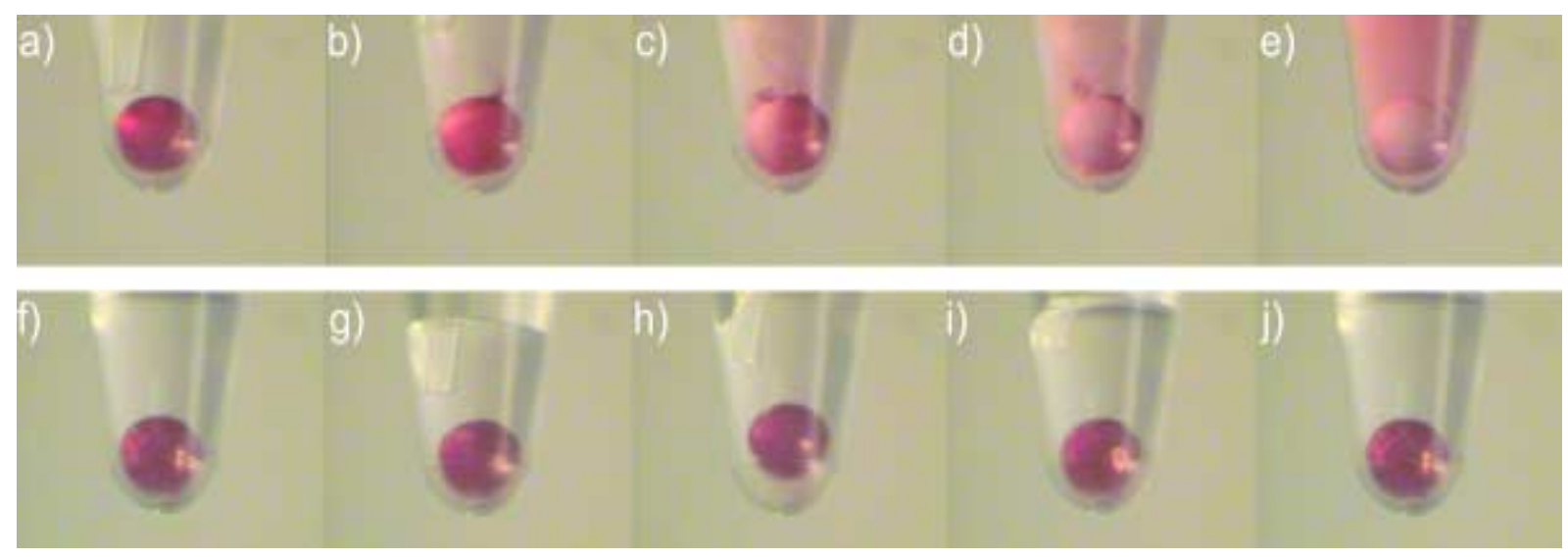

Figure 2 


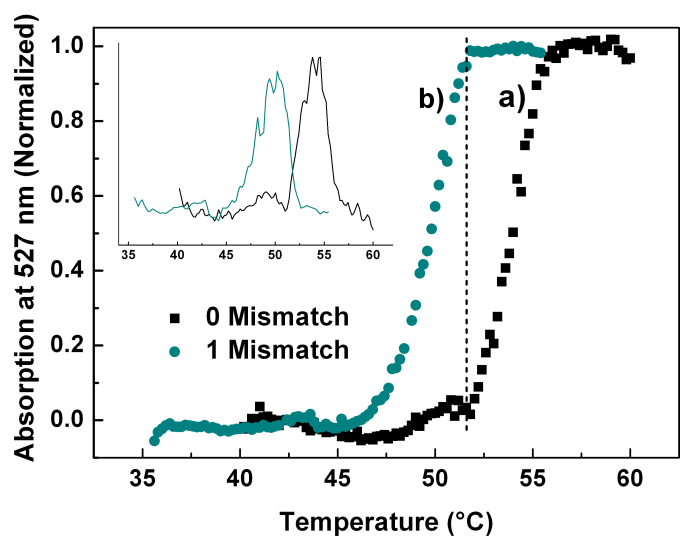

Figure 3 


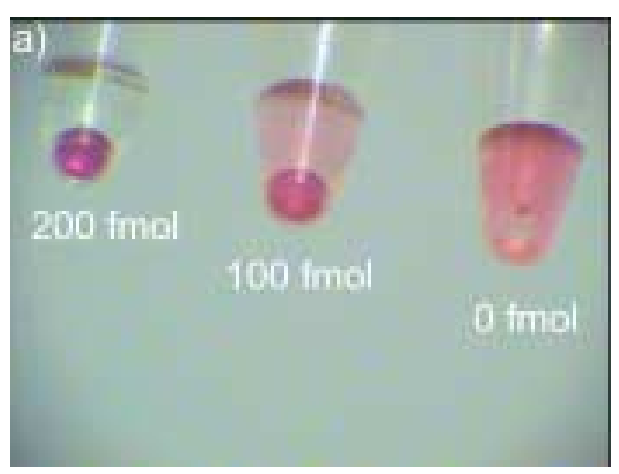

Figure 4a 


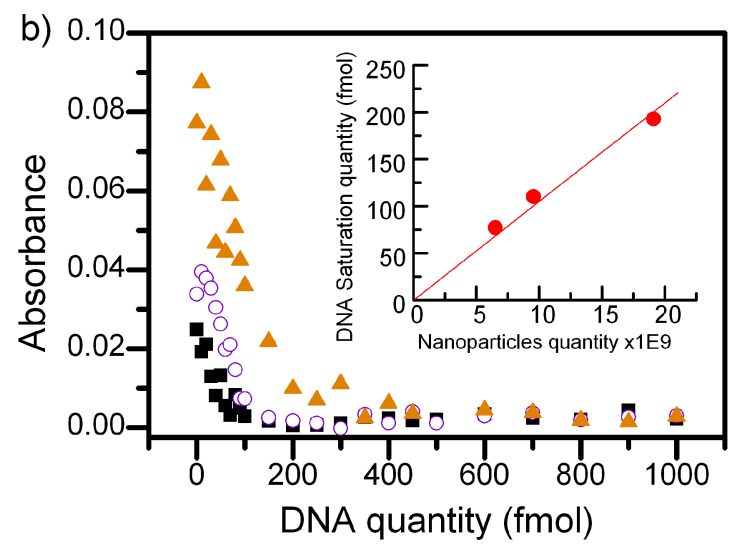

Figure $4 b$ 


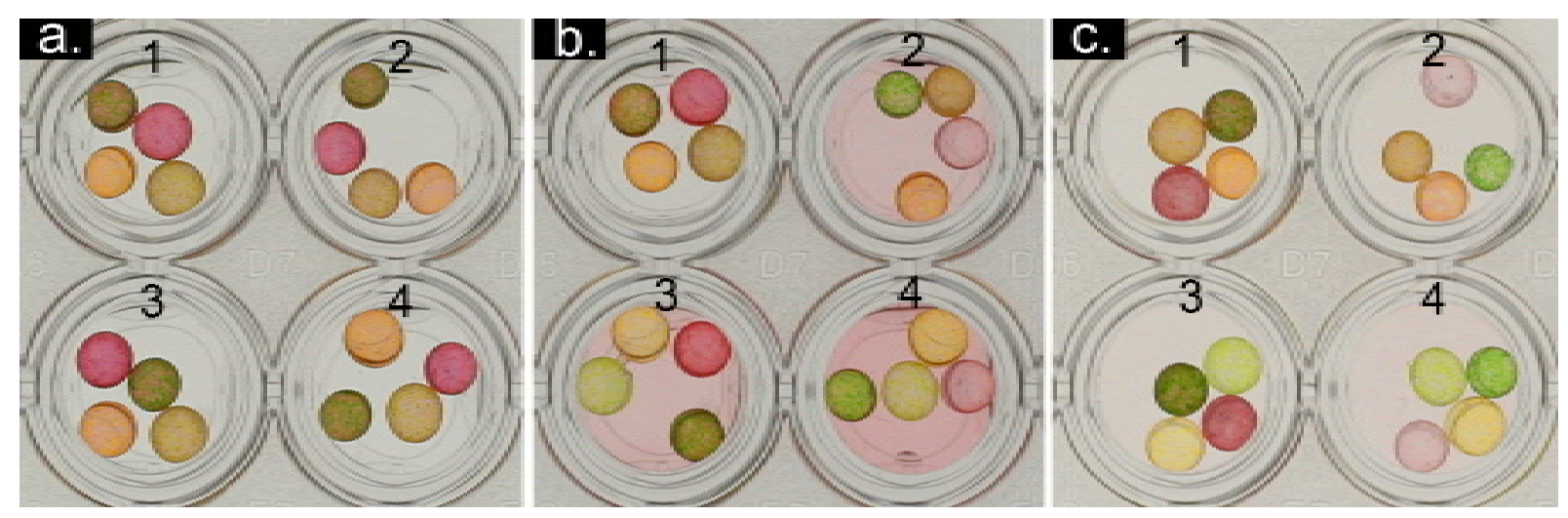

Figure 5 